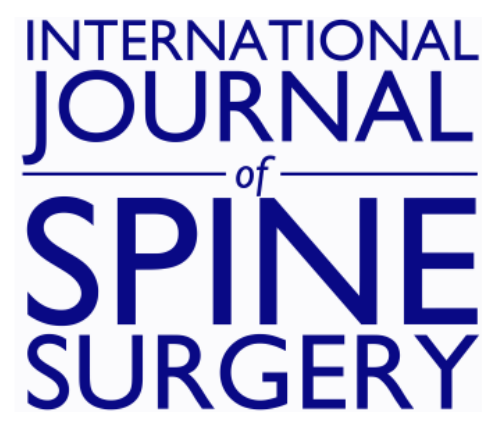

\title{
Biomechanical Stability of the Sacroiliac Joint with Differing Implant Configurations in a Synthetic Model
}

Andrew L. Freeman, Joan E. Bechtold and David W. Polly, Jr

Int J Spine Surg 2021, 15 (5) 853-861

doi: https://doi.org/10.14444/8117

http://ijssurgery.com/content/15/5/853

This information is current as of April 26, 2023.

Email Alerts Receive free email-alerts when new articles cite this article. Sign up at:

http://ijssurgery.com/alerts 


\title{
Biomechanical Stability of the Sacroiliac Joint with Differing Implant Configurations in a Synthetic Model
}

\author{
ANDREW L. FREEMAN, MS, ${ }^{1}$ JOAN E. BECHTOLD, PHD,${ }^{1,2,3}$ DAVID W. POLLY JR., MD ${ }^{2}$ \\ ${ }^{\prime}$ Department of Biomedical Engineering, University of Minnesota, Minneapolis, Minnesota, ${ }^{2}$ Department of Orthopaedic Surgery, University of Minnesota, \\ Minneapolis, Minnesota, ${ }^{3}$ Minneapolis Medical Research Foundation and Excelen Center for Bone \& Joint Research and Education, Minneapolis, Minnesota
}

\begin{abstract}
Background: The sacroiliac joint (SIJ) is responsible for $15 \%-30 \%$ of chronic low back pain and fusion is increasingly used to alleviate chronic SIJ pain in adults. However, questions remain as to the most effective implant patterns to stabilize the joint. The objective of this biomechanical study was to evaluate how different implant spacing, configuration and quantity effect range of motion (ROM) of a synthetic foam SIJ model.

Methods: Triangular SIJ fusion implants were tested in six patterns using three implants, and two patterns with two implants $(\mathrm{n}=5 /$ pattern $)$. Linear, triangular, and angled $\left(10^{\circ}\right.$ or $\left.20^{\circ}\right)$ implant patterns were used with spacing of 13 or $22 \mathrm{~mm}$ between implants. Implants were placed through a denser polyurethane foam block $\left(0.32 \mathrm{~g} / \mathrm{cm}^{3}\right)$ representing the ilium and into a less dense block representing the sacrum $\left(0.16 \mathrm{~g} / \mathrm{cm}^{3}\right)$ to a depth $30 \mathrm{~mm}$ with a 2-mm gap between blocks. Cyclic torsion and shear testing were conducted for 10,000 cycles and ROM was recorded. Pullout testing was conducted on non-cycled $(\mathrm{n}=10)$ implants and individually on all implants after construct cycling.

Results: ROM was significantly lower for all 22-mm implant patterns compared to the $13 \mathrm{~mm}$ linear pattern after cyclic loading in both torsion and shear. The use of three implants provided $60 \%$ and $86 \%$ greater stability, respectively, than two implants with spacing of 22 and $13 \mathrm{~mm}$. Pullout resistance followed similar trends with the lowest forces occurring in closely spaced patterns that used two implants.

Conclusions: This study demonstrated that the use of three implants and maximizing the spacing between implants might provide greater stability to the SIJ. If implants must be placed closely, then nonlinear patterns may improve construct stability.
\end{abstract}

Biomechanics

Keywords: biomechanics, fusion, fixation, range of motion, cycling, implant spacing, sacroiliac joint stabilization, minimally invasive surgery

\section{INTRODUCTION}

Recent studies have demonstrated that sacroiliac joint (SIJ) pain is a significant public health burden responsible for $15 \%-30 \%$ of chronic low back pain. ${ }^{1-4}$ Quality of life comparisons with common medical conditions have shown SIJ patients to be in the lowest $15 \%$, indicating the potential for drastic improvements in patient satisfaction with appropriate interventions. ${ }^{5}$ It appears that SIJ dysfunction has been an overlooked disease with misdiagnosis resulting in unnecessary and detrimental surgical interventions in the neighboring lumbar spine and hip joints.

Low treatment rates may be due to lack of awareness of the SIJ as a primary source of pain, difficulties in definitive diagnosis of SIJ pain, and until recently, the lack of effective options for surgical intervention. The treatment of SIJ dysfunc- tion is gaining in popularity due to the recent availability of surgical treatment options that focus on minimizing motion at the joint to provide pain relief. A lateral transiliac approach is most frequently used for SIJ fusions with screw-based systems available from multiple manufacturers, although a unique fixation system consisting of triangular titanium implants with an osteoconductive coating is also commonly used (Figure 1). There is a substantial amount of published literature supporting the use of the triangular implants including retrospective case series, reviews, pooled analyses, and 3 prospective clinical trials. ${ }^{6-23}$ The results from these studies are encouraging, as patients treated with SIJ fusion have demonstrated significant improvements in pain, disability, and quality of life when compared with patients that received nonsurgical treatment. 

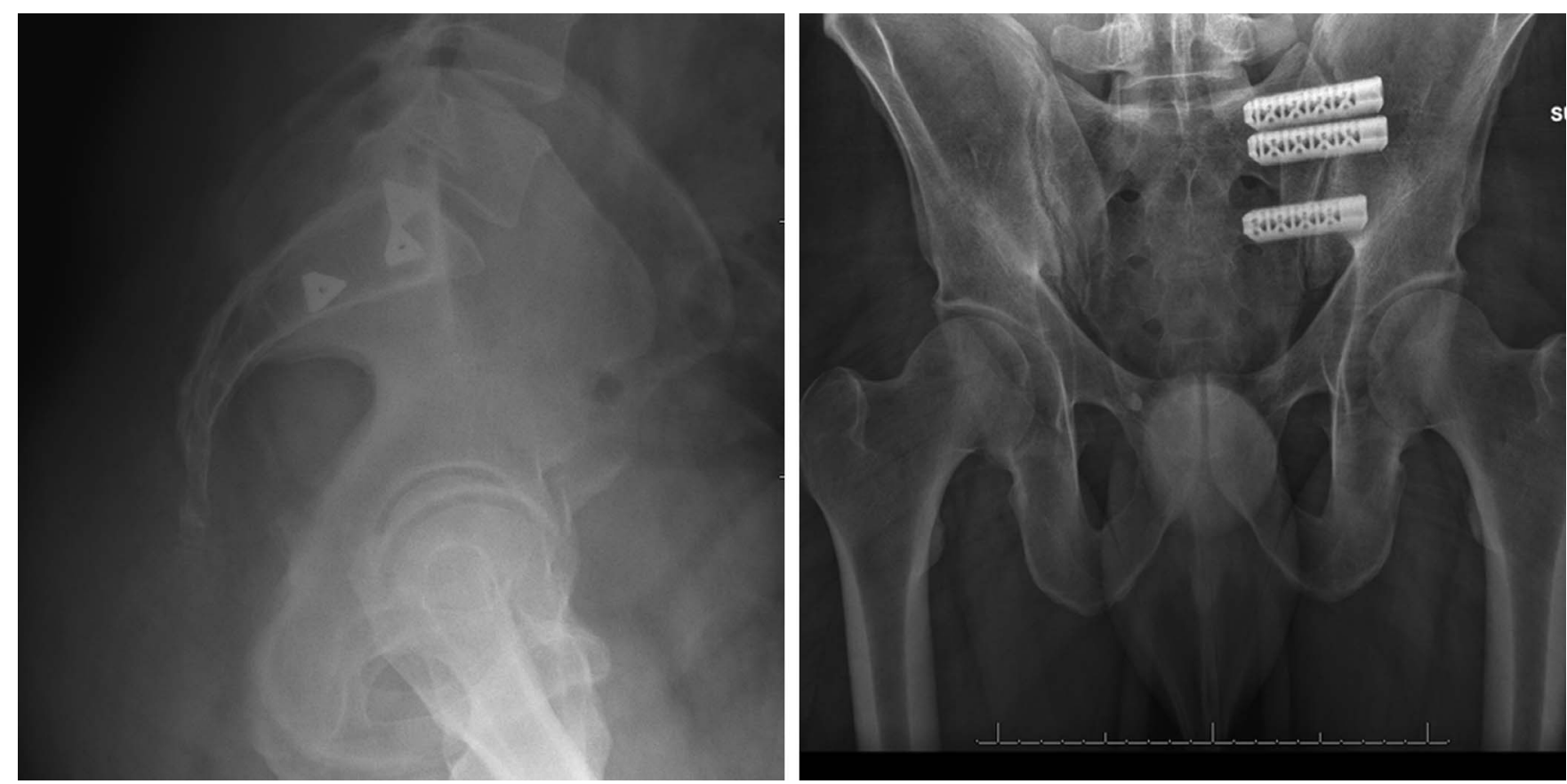

Figure 1. (Left) Lateral and (right) anterior-posterior radiograph demonstrating the placement of 3 triangular titanium implants.

Despite the effectiveness of surgical treatment of the SIJ, a loss of fixation in the sacrum is a concern among surgeons and has been reported as a common fixation failure mode. ${ }^{20,24}$ Sacral bone density has been shown to vary with the highest density in the S1 body and regions of decreased density in the lateral and central sacral ala. ${ }^{24,25}$ Effective stabilization of the SIJ has been previously demonstrated in biomechanical studies with triangular implants. Soriano-Baron et $\mathrm{al}^{26}$ compared implants placed in line to those with an angled transarticular placement toward an area of higher sacral bone density. Both techniques significantly reduced motion and, although not significant, the transarticular placement provided greater stability on average. The triangular implants have also recently been studied using a finite element model to quantify the effects of implant orientation, superior implant length, and implant number on SIJ range of motion (ROM) ${ }^{27}$ The model demonstrated that the use of 3 implants, with the superior implant extending to the sacral midline, provided the greatest SIJ stability.

While fixation of the SIJ has demonstrated clinical effectiveness, questions remain as to the most effective implant configurations to stabilize the joint. The purpose of this study was to biomechanically evaluate the stability of different implant placement patterns and quantities in a synthetic foam SIJ model. The SIJ constructs were subjected to 2 different cyclic loading modalities which simulated nutation, counternutation, and shear loading.

\section{MATERIALS AND METHODS}

\section{SIJ Foam Model}

The bone density of the ilium is 2 times greater than the sacrum in vivo. Cellular foam blocks with densities of 0.32 and $0.16 \mathrm{~g} / \mathrm{cm}^{3}$ were therefore used to represent the ilium and sacrum, respectively (Sawbones, Vashon Island, WA, model \#1522-12 and \#1522-10). ${ }^{28}$ The foam was cut into blocks measuring $85.7 \times 61.9 \times 40 \mathrm{~mm}$ using a table saw to ensure consistent dimensions.

Implant configurations were chosen from those used clinically by the surgeon author (DWP) to evaluate different implant spacing, patterns, and quantities. Three-implant constructs were tested in 6 different patterns and 2-implant constructs were tested in 2 patterns. The 3-implant constructs consisted of linear and triangular patterns with 13and 22-mm spacing between implants (Figure 2). The linear 22-mm pattern was also tested with the peripheral implants angled outwards at $10^{\circ}$ and $20^{\circ}$. In the triangular patterns, the middle implant was offset $10 \mathrm{~mm}$ from the outer 2 implants. The linear 13- and 22-mm patterns were also tested using only 2 implants. All implants were placed to a depth of $30 \mathrm{~mm}$ into the sacral foam. 


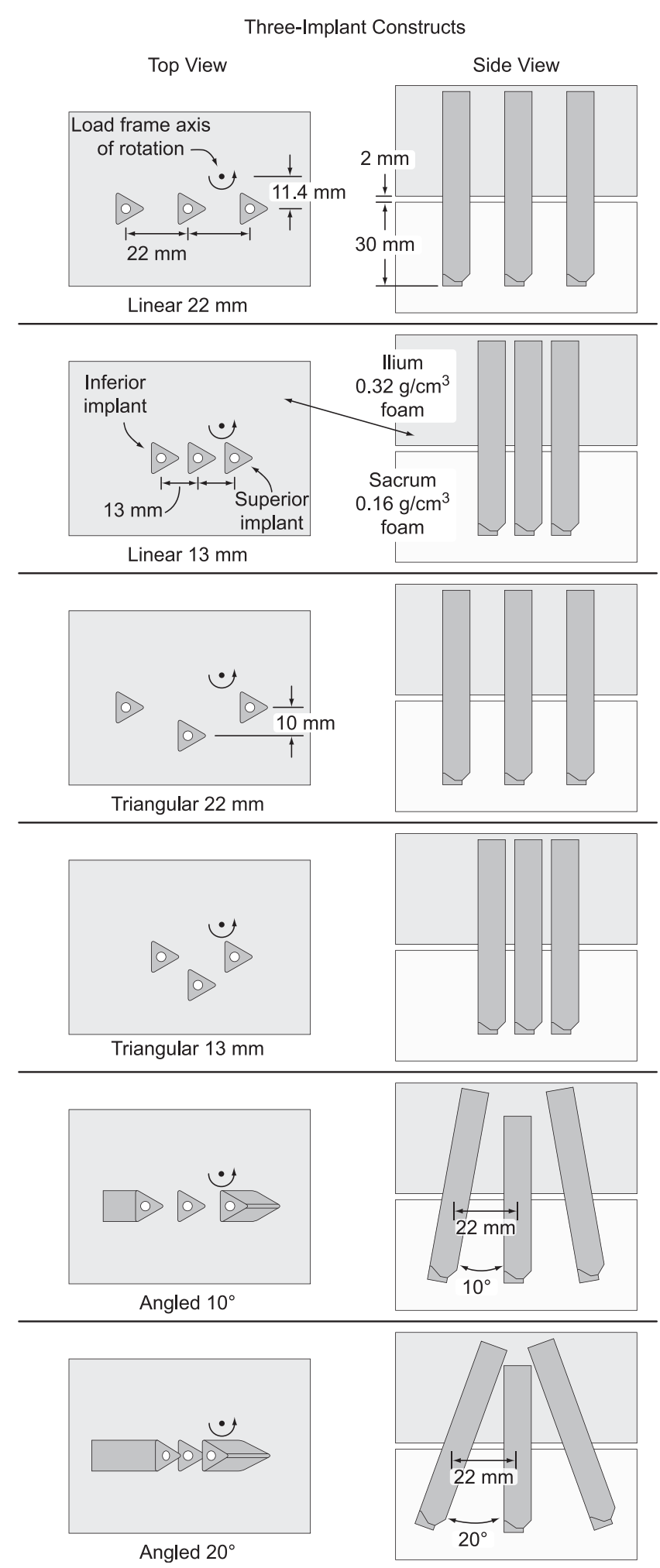

Figure 2. Configurations of constructs tested with 3 implants.

Pilot holes were drilled through the ilial foam blocks using a computer numerical control milling machine with a 7-mm drill bit. For the sacral blocks, holes were drilled several millimeters deeper than the final implant placement depth. Spacing of the implants was the same for both torsion and shear testing, although the shear constructs were angled $50^{\circ}$ from horizontal to represent the slope of the sacrum during standing. ${ }^{29}$

The ilial and sacral blocks were aligned, clamped together, and a triangular broach was pounded through each pilot hole; residual foam particles were removed with a vacuum. A gap of $2 \mathrm{~mm}$ was maintained between the 2 blocks using aluminum spacers. Triangular titanium implants that were 70 $\mathrm{mm}$ in length (iFuse, SI-BONE, San Jose, CA) were pounded to a depth of $30 \mathrm{~mm}$ into the sacral foam. The $10^{\circ}$ and $20^{\circ}$ angled patterns used two $70-\mathrm{mm}$ peripheral implants with a $60-\mathrm{mm}$ implant in the middle position.

The 3-implant foam block constructs were tested with 6 patterns in torsion $(\mathrm{n}=5 /$ pattern $)$ and with 4 patterns in shear $(\mathrm{n}=5 /$ pattern $)$; the $10^{\circ}$ and $20^{\circ}$ angled patterns were not tested in shear (Table). The 2-implant constructs with 13 - and 22-mm patterns were only tested in torsion $(\mathrm{n}=5 /$ pattern $)$.

\section{Cyclic Torsion Testing}

Vises were secured to a biaxial load frame (858 Mini Bionix, MTS, Eden Prairie, MN) using custom fixtures to position the axis of rotation approximately $11 \mathrm{~mm}$ posterior to the superior implant (Figure 3). Cyclic torsion testing was conducted using a sinusoidal waveform at $\pm 7 \mathrm{Nm}$ for 10000 cycles at $1 \mathrm{~Hz}$. ROM tests were conducted at a slower rate of $0.5 \mathrm{Nm} / \mathrm{s}$ to $\pm 7 \mathrm{Nm}$ following 10 cycles of initial preconditioning ( 0 cycles) and at 10000 cycles; timed data were acquired at $50 \mathrm{~Hz}$.

\section{Cyclic Shear Testing}

Shear testing was performed by positioning the long axis of the implants perpendicular to the actuator of the load frame with the test block construct angled $50^{\circ}$ from horizontal to represent the slope of the sacrum during standing. The blocks were tightened with the load frame in load control to ensure that no unintended loads were induced. Cyclic shear testing was conducted using a sinusoidal waveform in compression from $-300 \pm 200 \mathrm{~N}$ for 10000 cycles at $1 \mathrm{~Hz}$. ROM tests were conducted for 1 cycle at a slower rate of $50 \mathrm{~N} / \mathrm{s}$ from $-300 \pm 200 \mathrm{~N}$ after 10 cycles of initial preconditioning ( 0 cycles) and at 10000 cycles; timed data were acquired at $50 \mathrm{~Hz}$. 
Table. Sample sizes used for testing in each implant pattern and loading modality.

\begin{tabular}{|c|c|c|c|c|c|c|}
\hline & Linear 13 mm & Linear 22 mm & Triangular $13 \mathrm{~mm}$ & Triangular $22 \mathrm{~mm}$ & Angled $10^{\circ}$ & Angled $20^{\circ}$ \\
\hline \multicolumn{7}{|c|}{ 3-implant constructs - sample sizes } \\
\hline \multicolumn{7}{|c|}{ Torsion } \\
\hline Cyclic & 5 & 5 & 5 & 5 & 5 & 5 \\
\hline Pullout & 15 & 15 & 15 & 15 & 15 & 15 \\
\hline \multicolumn{7}{|l|}{ Shear } \\
\hline Cyclic & 5 & 5 & 5 & 5 & NA & NA \\
\hline Pullout & 15 & 15 & 15 & 15 & NA & NA \\
\hline \multicolumn{7}{|c|}{ 2-implant constructs - sample sizes } \\
\hline \multicolumn{7}{|c|}{ Torsion } \\
\hline Cyclic & 5 & 5 & NA & NA & NA & NA \\
\hline Pullout & 10 & 10 & NA & NA & NA & NA \\
\hline
\end{tabular}

Abbreviation: NA, not available.

\section{Pullout Testing}

After the completion of cyclic testing, the ilial foam was cut using a band saw between each implant to allow for independent pullout tests on each implant (Figure 3). A machine screw was threaded into the open end of the implant, and the head of the screw was placed into a pullout fixture attached to the load frame actuator. The sacral block was secured with clamps to an aluminum plate. The angled constructs were clamped in a vise with the implant positioned vertically to allow for pullout in line with the primary axis of the implant. Pullout tests were also conducted on noncycled control implants $(\mathrm{n}=10)$ placed $30 \mathrm{~mm}$ deep into a block of sacral foam. Pullout testing was conducted at $5 \mathrm{~mm} / \mathrm{min}$ with data acquisition at $30 \mathrm{~Hz}$.

\section{Data Analysis}

Custom computer code (Matlab, Mathworks, Natick, MA) was used to calculate ROM in torsion and shear at 0 and 10000 cycles. Construct ROM was calculated as the difference between the maximum and minimum rotation (torsion) or displacement (shear). Peak pullout forces were also calculated.

\section{Statistical Methods}

Statistical differences in torsion and shear ROM were evaluated by performing a 2-way repeated measures analysis of variance (ANOVA; Prism 5, GraphPad, San Diego, CA). Torsion ROM data for the 2- versus 3-implant constructs were also analyzed using a 2-way repeated measures ANOVA. The pullout data between all configurations were evaluated using a standard ANOVA. Statistical significance was declared at $P<.05$.

\section{RESULTS}

\section{Torsion-ROM}

The ROM was significantly lower for the linear and triangular 22-mm patterns than both the linear and triangular $13-\mathrm{mm}$ patterns at 0 and 10000 cycles $(P<.05$, Figure 4$)$. The pattern with $10^{\circ}$ implant angles had significantly less ROM than the

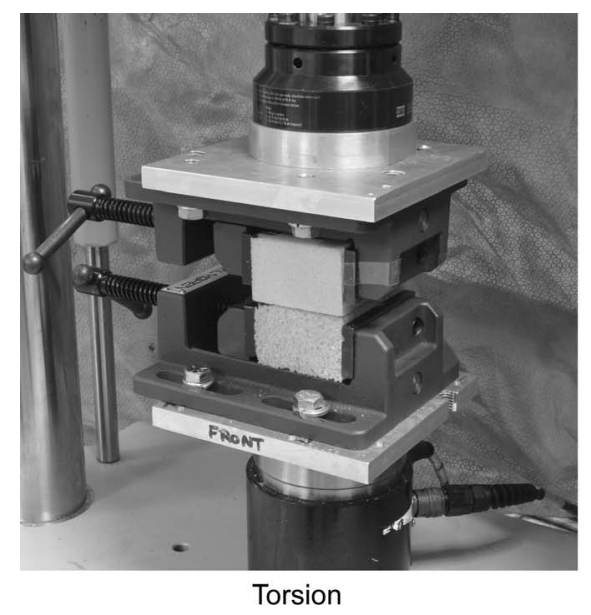

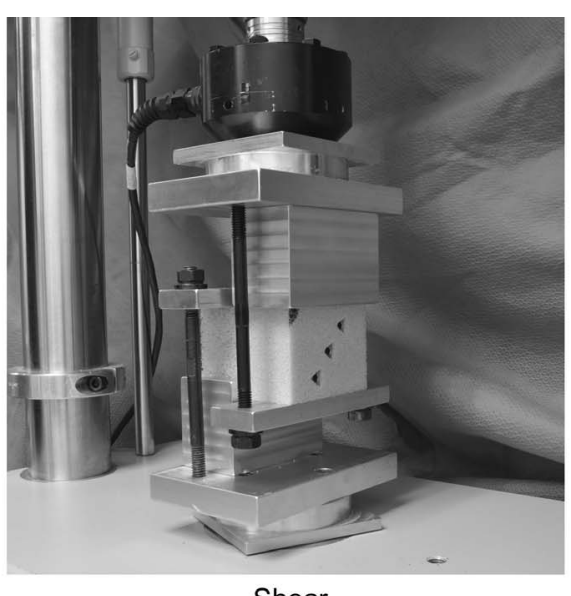

Shear

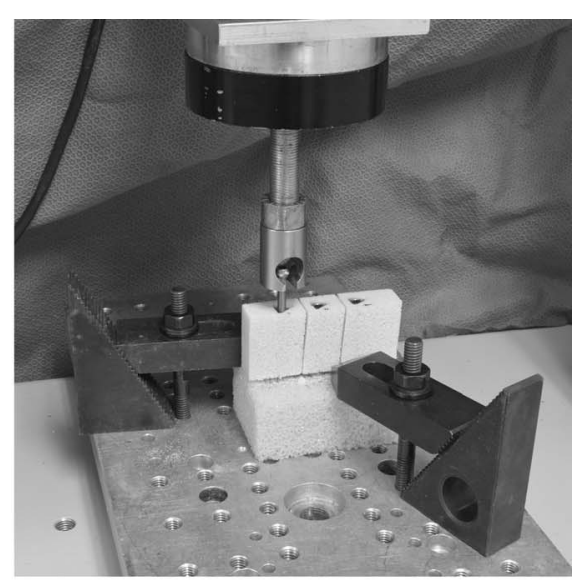

Pullout

Figure 3. Test setups for cyclic torsion, cyclic shear, and implant pullout tests. 


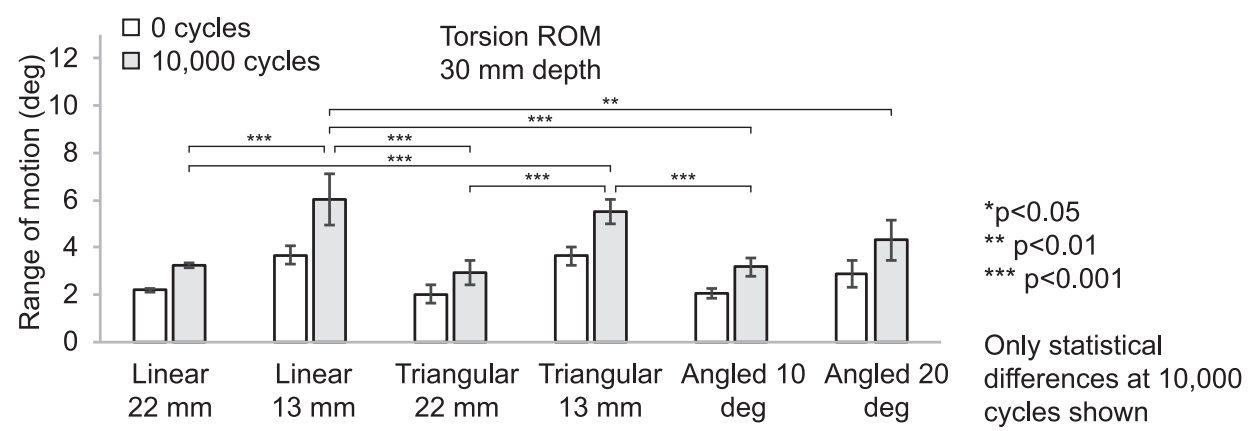

Figure 4. Construct range of motion (average $\pm \mathrm{SD}$ ) in torsion for all patterns. ${ }^{\star \star} P<.01,{ }^{\star \star *} P<.001$.

linear and triangular $13-\mathrm{mm}$ patterns at both 0 and 10000 cycles $(P<.01)$. The pattern with $20^{\circ}$ implant angles only experienced a significant reduction in ROM versus the linear $13-\mathrm{mm}$ pattern at 10000 cycles $(P<.01)$. The initial ROMs for patterns with $22-\mathrm{mm}$ implant spacing ranged from $2.0 \pm 0.4^{\circ}$ for the triangular pattern to $2.9 \pm 0.6^{\circ}$ for the pattern with $20^{\circ}$ implant angles. ROM increases for the 22- $\mathrm{mm}$ implant spacing ranged from $0.9^{\circ}$ (triangular) to $1.4^{\circ}$ (angled $20^{\circ}$ ) after cyclic loading. The two $13-\mathrm{mm}$ patterns had similar initial ROMs of $\sim 3.6^{\circ}$, which increased to $5.5 \pm 0.5^{\circ}$ for the $13-\mathrm{mm}$ triangular and $6.0 \pm 1.1^{\circ}$ for the $13-\mathrm{mm}$ linear patterns after cyclic loading. The linear 13mm pattern allowed $81 \%$ more ROM than the 22 $\mathrm{mm}$ triangular pattern at 0 cycles and allowed $106 \%$ more ROM after 10000 cycles.

\section{Torsion-ROM, 2 Versus 3 Implants}

The 2-implant patterns exhibited greater ROM at both 0 and 10000 cycles than the 3 -implant patterns, although differences were only significant at 10000 cycles (Figure 5). The 2-implant patterns had noticeably more toggle between the blocks than 3-implant patterns at the completion of cyclic

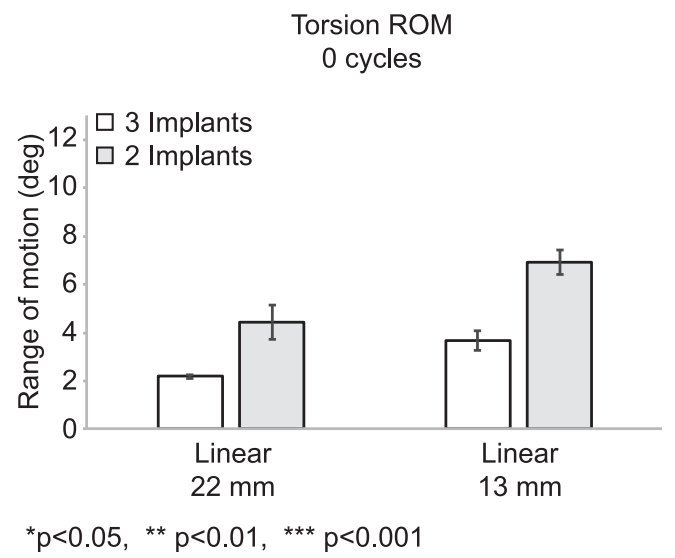

loading, particularly in the $13-\mathrm{mm}$ linear pattern. Gap formation and widening of the broached holes was observed in the sacral foam of the 2-implant linear 13-mm pattern after cyclic loading. After 10000 cycles, the 3-implant linear 22-mm pattern had a ROM of $3.3 \pm 0.1^{\circ}$, while the 2-implant pattern was $8.4 \pm 2.2^{\circ}(P<.05)$. The 2 -implant 13 $\mathrm{mm}$ linear pattern had a large increase in ROM after 10000 cycles to $43.8 \pm 6.4^{\circ}$, while the 3 implant pattern was $6.0 \pm 1.1^{\circ}(P<.001)$.

\section{Shear}

ROM was significantly greater for the linear 13$\mathrm{mm}$ pattern than all other patterns at both 0 and 10000 cycles $(P<.001$, Figure 6$)$. ROM for the $13-$ $\mathrm{mm}$ linear pattern at 10000 cycles was $0.35 \pm 0.02$ $\mathrm{mm}$ compared with $0.27 \pm 0.02 \mathrm{~mm}$ for the linear $22 \mathrm{~mm}, 0.30 \pm 0.01 \mathrm{~mm}$ for the triangular $13 \mathrm{~mm}$, and $0.27 \pm 0.02 \mathrm{~mm}$ for the triangular $22 \mathrm{~mm}$, respectively.

\section{Pullout}

The noncycled control implants had an average pullout force of $70 \pm 16 \mathrm{~N}$ (Figures 7 and 8). The

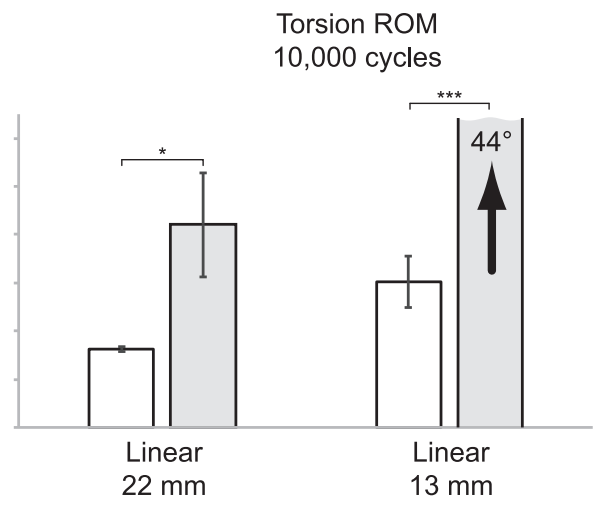

Figure 5. Torsion range of motion (average \pm SD) comparing configurations using 2 versus 3 implants at 0 and 10000 cycles. ${ }^{*} P<.05$, ${ }^{* * *} P<.001$. 


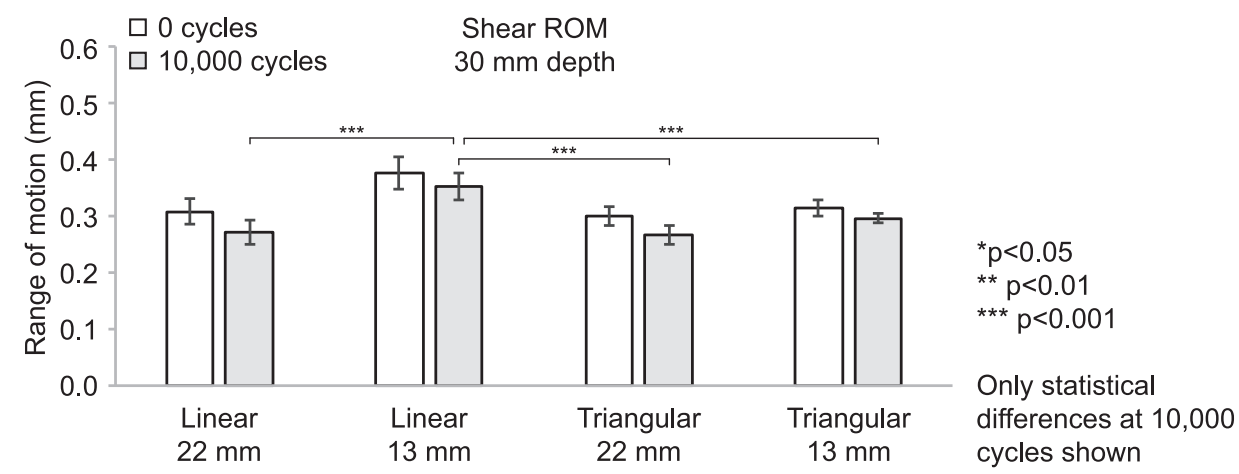

Figure 6. Construct range of motion (average \pm SD) in shear for linear and triangular patterns. ${ }^{\star \star \star} P<.001$.

lowest pullout forces for 3-implant constructs occurred in the linear $13-\mathrm{mm}$ pattern at $32 \pm 17$ $\mathrm{N}$, while the greatest force was in the angled $10^{\circ}$ pattern at $74 \pm 28 \mathrm{~N}$. The linear and triangular 22$\mathrm{mm}$ patterns had pullout forces of $59 \pm 21$ and 49 $\pm 18 \mathrm{~N}$, respectively. Pullout forces in the 2-implant patterns were $4 \pm 5$ and $39 \pm 15 \mathrm{~N}$ for the 13- and 22-mm spacing, respectively

\section{DISCUSSION}

The results of this study suggest that there are several implant placement strategies that may be beneficial to enhance the stability of SIJ fusions. The spacing between implants (13 or $22 \mathrm{~mm}$ ) had a larger effect on the biomechanical performance than the implant pattern (linear versus triangular) in both torsion and shear testing. The test configurations with 22-mm spacing between implants had significantly less ROM and greater pullout loads than configurations with 13-mm spacing. There were no statistical differences in the torsion and shear outcome data between the linear and triangular patterns with $22-\mathrm{mm}$ spacing. At the $13-\mathrm{mm}$ spacing, the triangular pattern tended to perform better than the linear pattern, and there were several significant differences in ROM and pullout data for both torsion and shear. These data indicate that greater stability can be expected when spacing between implants is increased.

Although 3 implants are recommended to provide improved SIJ stability, there are certain cases where this may not be feasible and only 2 implants can be placed. In a recently completed randomized controlled trial using the implant evaluated in the present study, $5 \%$ of patients received 2, 91\% received 3 , and $4 \%$ received 4 implants. ${ }^{20}$ To determine how the number of implants may affect SIJ stability, the present study tested 2-implant constructs cyclically in torsion with $13-$ and $22-\mathrm{mm}$ spacing between implants. The 2-implant constructs had greater motion and reduced pullout strength than the 3-implant constructs with significant

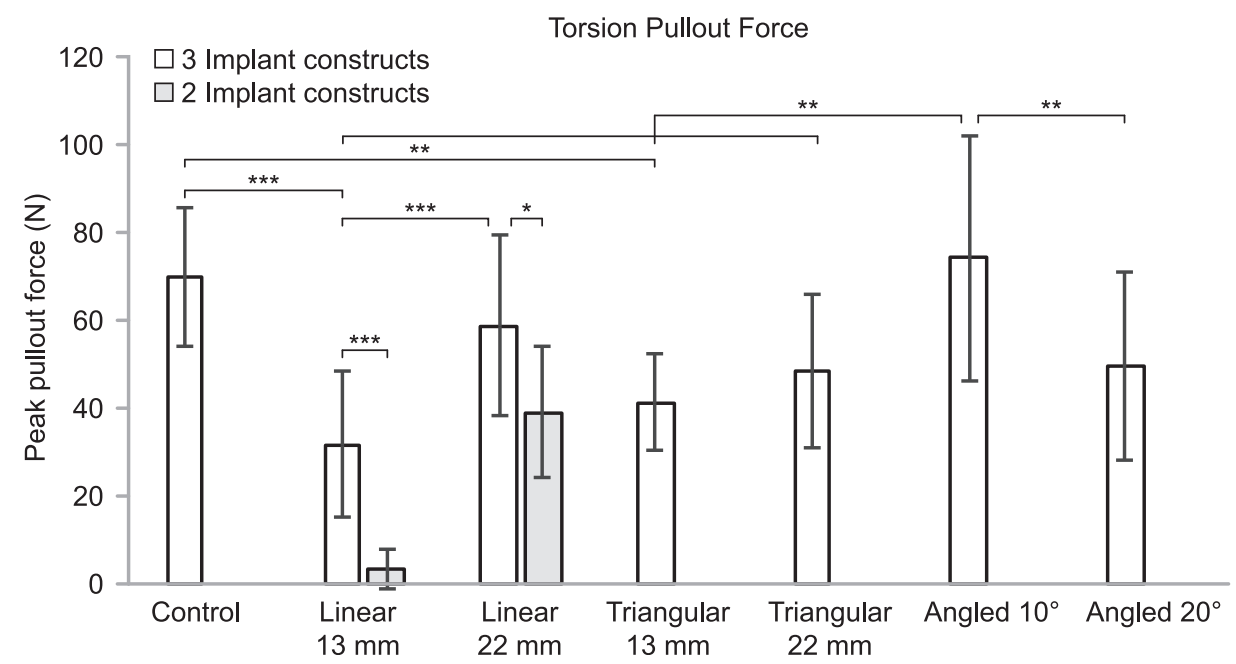

Figure 7. Peak pullout force (average $\pm \mathrm{SD})$ on noncycled control implants $(\mathrm{n}=10)$ and after cyclic torsion testing $\left(\mathrm{n}=15\right.$ for each pattern). ${ }^{*} P<.05,{ }^{* \star} P<.01,{ }^{* \star \star} P$ $<.001$. 


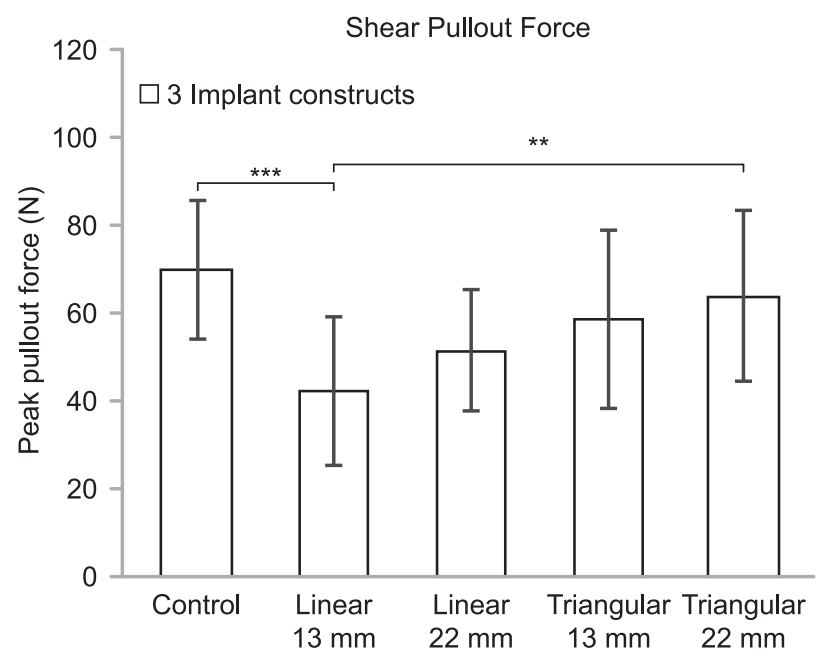

Figure 8. Peak pullout force (average $\pm S D$ ) on noncycled control implants (n $=10)$ and after cyclic shear testing $(n=15$ for each pattern).

differences after 10000 cycles. At the completion of cyclic loading, the 22- and 13-mm 2-implant constructs allowed 2.5 to 7.3 times more ROM, respectively, than the 3 -implant constructs. The 2implant constructs with $13-\mathrm{mm}$ spacing were extremely loose with a $44^{\circ}$ ROM and almost no resistance to pullout forces $(4 \mathrm{~N})$. Based on these data, the use of 3 implants is advised, but if only 2 implants can be used, they should be spaced as far apart as possible to provide greater SIJ stability.

The ROM values in the present study for both torsion and shear were consistent with previously published cadaveric biomechanical studies. ${ }^{26,30-32}$ In a cadaveric study, Lindsey et $\mathrm{al}^{30}$ reported flexionextension $\mathrm{ROM}$ ranging from $1.6^{\circ}$ to $6.4^{\circ}$ for specimens implanted with 3 triangular titanium implants, which compares favorably to the $2.0^{\circ}-$ $6.9^{\circ}$ ROMs for the noncycled 2- and 3-implant constructs in the present study. The vertical displacement of the SIJ was measured in a cadaveric study by Dujardin et $\mathrm{al}^{32}$ to be 0.22 to $0.35 \mathrm{~mm}$ under an applied load of $310 \mathrm{~N}$. Although a higher shear load was used in the current study $(500 \mathrm{~N})$, the displacement of our SIJ construct was similar with a range of 0.30 to $0.38 \mathrm{~mm}$. The $7 \mathrm{Nm}$ moment applied during torsion testing was similar in magnitude to other cadaveric biomechanical studies where specimens were cyclically loaded using moments from 3.75 to $7.5 \mathrm{Nm}$ or tested for flexibility (no cycling) at $7.5 \mathrm{Nm} \cdot{ }^{26,30,31}$

Authors of a finite element analysis (FEA) of the SIJ evaluated in line and transarticular placement of triangular titanium implants with a varying number of implants (1, 2, or 3) and superior implant lengths. ${ }^{27}$ Authors of this FEA study found a reduction in SIJ ROM using a transarticular implant placement, longer superior implants, and a greater number of implants. Compared with in-line placement, the transarticular technique only affects the middle implant in that the starting point is ventral to the anterior sacral body and aimed posteriorly across the cartilaginous area of the SIJ. The triangular configurations in the present study are like a transarticular placement but maintain parallel positioning of all implants. The data from the current study support the findings of the FEA study in that SIJ stability was improved with a greater number of implants, increased spacing between implants, and nonlinear implant configurations.

As with all biomechanical studies, there are several limitations that must be considered. A foam model was chosen to provide a simplified simulation of the SIJ so that variability could be minimized between test constructs. The implant spacing (13 and $22 \mathrm{~mm}$ ), angulation (parallel, $10^{\circ}$, or $20^{\circ}$ ), and offset $(10 \mathrm{~mm})$ were based on the clinical experience from more than 200 primary SIJ fusion cases performed by the surgeon author. The implant configurations were chosen to represent a range of options that are suitable for differing patient anatomy. The use of cadaveric specimens would have introduced significant variations in bone quality, anatomy, and native ROM that would have made consistent implant placement difficult and increased the variability in the data, which may have masked differences between test groups. The loading used in this study was not intended to replicate the complex in vivo motion of the SIJ but to simulate the worst-case loading of implants. Nutation and counternutation (torsional loading) is the largest motion in the SIJ and has been suggested as being responsible for implant loosening; therefore, more tests were conducted in this loading mode. ${ }^{33}$ This model is also not capable of characterizing any biological responses, such as bone ingrowth, that occur in vivo. Although the quantitative results from this study may differ from clinical values, the qualitative differences between constructs are expected to behave similarly in the human SIJ.

This biomechanical study has demonstrated that the stability of SIJ fusions may be improved by considering how implants are configured. The number of implants had the largest effect on 
construct stability, and the use of 3 implants instead of 2 is preferable for both short- and long-term stability. Increasing the spacing between implants reduced ROM, particularly when only 2 implants were used. The use of nonlinear implant configurations may provide additional stability. Placement of implants in nonlinear and angled configurations may require the use of advanced imaging and robotic navigation systems. The application of these results to clinical use should be further evaluated in future studies.

\section{REFERENCES}

1. Sembrano JN, Polly DW. How often is low back pain not coming from the back? Spine (Phila Pa 1976). 2009;34(1):E27E32.

2. Bernard TN, Kirkaldy-Willis WH. Recognizing specific characteristics of nonspecific low back pain. Clin Orthop Relat Res. 1987;(217):266-280.

3. Maigne JY, Aivaliklis A, Pfefer F. Results of sacroiliac joint double block and value of sacroiliac pain provocation tests in 54 patients with low back pain. Spine (Phila Pa 1976). 1996;21(16):1889-1892.

4. Schwarzer AC, Aprill CN, Bogduk N. The sacroiliac joint in chronic low back pain. Spine (Phila Pa 1976). 1995;20(1):3137.

5. Cher D, Polly D, Berven S. Sacroiliac joint pain: burden of disease. Med Devices Auckl NZ. 2014;7:73-81.

6. Zaidi HA, Montoure AJ, Dickman CA. Surgical and clinical efficacy of sacroiliac joint fusion: a systematic review of the literature. J Neurosurg Spine. 2015;23(1):59-66.

7. Sachs D, Capobianco R, Cher D, et al. One-year outcomes after minimally invasive sacroiliac joint fusion with a series of triangular implants: a multicenter, patient-level analysis. Med Devices Auckl NZ. 2014;7:299-304.

8. Sachs D, Capobianco R. Minimally invasive sacroiliac joint fusion: one-year outcomes in 40 patients. Adv Orthop. 2013;2013:536128. doi:10.1155/2013/536128

9. Sachs D, Capobianco R. One year successful outcomes for novel sacroiliac joint arthrodesis system. Ann Surg Innov Res. 2012;6(1):13. doi:10.1186/1750-1164-6-13

10. Rudolf L, Capobianco R. Five-year clinical and radiographic outcomes after minimally invasive sacroiliac joint fusion using triangular implants. Open Orthop J. 2014;8:375383.

11. Rudolf L. Sacroiliac joint arthrodesis-MIS technique with titanium implants: report of the first 50 patients and outcomes. Open Orthop J. 2012;6:495-502.

12. Cummings J, Capobianco RA. Minimally invasive sacroiliac joint fusion: one-year outcomes in 18 patients. Ann Surg Innov Res. 2013;7(1):12. doi:10.1186/1750-1164-7-12

13. Gaetani P, Miotti D, Risso A, et al. Percutaneous arthrodesis of sacro-iliac joint: a pilot study. J Neurosurg Sci. 2013;57(4):297-301.

14. Schroeder JE, Cunningham ME, Ross T, et al. Early results of sacro-iliac joint fixation following long fusion to the sacrum in adult spine deformity. HSS J Musculoskelet J Hosp Spec Surg. 2014;10(1):30-35.

15. Ledonio CG, Polly DW, Swiontkowski MF, et al.
Comparative effectiveness of open versus minimally invasive sacroiliac joint fusion. Med Devices Auckl NZ. 2014;7:187-193.

16. Ledonio CGT, Polly DW, Swiontkowski MF. Minimally invasive versus open sacroiliac joint fusion: are they similarly safe and effective? Clin Orthop. 2014;472(6):1831-1838.

17. Smith AG, Capobianco R, Cher D, et al. Open versus minimally invasive sacroiliac joint fusion: a multi-center comparison of perioperative measures and clinical outcomes. Ann Surg Innov Res. 2013;7(1). doi:10.1186/1750-1164-7-14

18. Heiney J, Capobianco R, Cher D. A systematic review of minimally invasive sacroiliac joint fusion utilizing a lateral transarticular technique. Int J Spine Surg. 2015;9:40. doi:10. $14444 / 204040$

19. Lingutla KK, Pollock R, Ahuja S. Sacroiliac joint fusion for low back pain: a systematic review and meta-analysis. Eur Spine J. 2016;25(6):1924-1931.

20. Polly DW, Swofford J, Whang PG, et al. Two-year outcomes from a randomized controlled trial of minimally invasive sacroiliac joint fusion vs. non-surgical management for sacroiliac joint dysfunction. Int J Spine Surg. 2016;10:28. doi: $10.14444 / 3028$.

21. Sturesson B, Kools D, Pflugmacher R, et al. Six-month outcomes from a randomized controlled trial of minimally invasive SI joint fusion with triangular titanium implants vs conservative management. Eur Spine J. 2017;26(3):708-719.

22. Duhon BS, Cher DJ, Wine KD, et al. Triangular titanium implants for minimally invasive sacroiliac joint fusion: a prospective study. Glob Spine J. 2016;6(3):257-269.

23. Dengler J, Duhon B, Whang P, et al. Predictors of outcome in conservative and minimally invasive surgical management of pain originating from the sacroiliac joint: a pooled analysis. Spine (Phila Pa 1976). 2017;42(21):1664-1673.

24. Hoel RJ, Ledonio CGT, Takahashi T, et al. Sacral bone mineral density (BMD) assessment using opportunistic CT scans. J Orthop Res. 2017;35(1):160-166.

25. Richards AM, Coleman NW, Knight TA, et al. Bone density and cortical thickness in normal, osteopenic, and osteoporotic sacra. J Osteoporos. 2010;2010:504078. doi:10. 4061/2010/504078

26. Soriano-Baron H, Lindsey DP, Rodriguez-Martinez N, et al. The effect of implant placement on sacroiliac joint range of motion: posterior versus transarticular. Spine (Phila $\mathrm{Pa}$ 1976). 2015;40(9):E525-E530.

27. Lindsey DP, Kiapour A, Yerby SA, et al. Sacroiliac joint stability: finite element analysis of implant number, orientation, and superior implant length. World J Orthop. 2018;9(3):14-23.

28. McLauchlan GJ, Gardner DL. Sacral and iliac articular cartilage thickness and cellularity: relationship to subchondral bone end-plate thickness and cancellous bone density. Rheumatol Oxf Engl. 2002;41(4):375-380.

29. Mehta VA, Amin A, Omeis I, et al. Implications of spinopelvic alignment for the spine surgeon. Neurosurgery. 2015;76(Suppl 1):S42-S56; discussion S56.

30. Lindsey DP, Perez-Orribo L, Rodriguez-Martinez N, et al. Evaluation of a minimally invasive procedure for sacroiliac joint fusion - an in vitro biomechanical analysis of initial and cycled properties. Med Devices Auckl NZ. 2014;7:131-137.

31. Shih YC, Beaubien BP, Chen Q, et al. Biomechanical evaluation of sacroiliac joint fixation with decortication. Spine J. 2018;18(7):1241-1249. doi:10.1016/j.spinee.2018.02.016

32. Dujardin FH, Roussignol X, Hossenbaccus M, et al. 
Experimental study of the sacroiliac joint micromotion in pelvic disruption. J Orthop Trauma. 2002;16(2):99-103.

33. Vleeming A, Schuenke MD, Masi AT, et al. The sacroiliac joint: an overview of its anatomy, function and potential clinical implications. J Anat. 2012;221(6):537-567.

Disclosures and COI: The authors acknowledge SI Bone for donation of the implants and financial support.

Corresponding Author: Andrew L. Freeman, MS, Department of Biomedical Engineering, Uni- versity of Minnesota, 700 10th Ave S \#118, Minneapolis, MN 55415. Phone: (612) 454-4243; Email: freem085@umn.edu.

Published 3 December 2021

This manuscript is generously published free of charge by ISASS, the International Society for the Advancement of Spine Surgery. Copyright (C) 2021 ISASS. To see more or order reprints or permissions, see http://ijssurgery.com. 